\title{
Simulation-based research in emergency medicine in Canada: Priorities and perspectives
}

Timothy Chaplin (D, MD*; Brent Thoma, MD, MA, MSc ${ }^{\dagger}$; Andrew Petrosoniak, MD, MSc (MedEd) ${ }^{\ddagger}$; Kyla Caners, MD ${ }^{\S}$; Tamara McColl, MDף; Chantal Forristal, MD**; Christa Dakin, MD $^{\text {t+; }}$ Jean-Francois Deshaies, $\mathrm{MD}^{\ddagger \neq}$; Eliane Raymond-Dufresne, MD $\S$; Mary Fotheringham, $\mathrm{MD}^{* *}$;

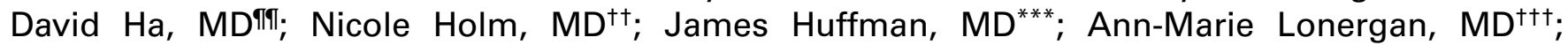

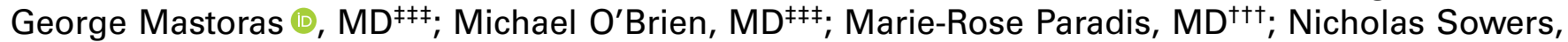
MD ${ }^{\S \S ; ~ E r r o l ~ S t e r n, ~ M D I T ा ; ~ A n d r e w ~ K . ~ H a l l ~(1), ~ M D, ~ M M E d * ~}$

\section{CLINICIAN'S CAPSULE}

What is known about the topic?

Simulation plays an important role in Canadian emergency medicine (EM) with applications in quality improvement, systems development, and medical education. What did this study ask?

Within EM, what simulation-based research is currently taking place, and what are the priority research themes for future study?

What did this study find?

Simulation in competency-based medical education, simulation for interdisciplinary and inter-professional learning, and simulation for summative assessment are the top priority research themes.

Why does this study matter to clinicians?

A focused research agenda, specific to Canadian EM, will ensure that the growth of simulation is both effective and efficient.

\section{ABSTRACT}

Objective: Simulation plays an integral role in the Canadian healthcare system with applications in quality improvement, systems development, and medical education. High-quality, simulation-based research will ensure its effective use. This study sought to summarize simulation-based research activity and its facilitators and barriers, as well as establish priorities for simulation-based research in Canadian emergency medicine (EM).

Methods: Simulation-leads from Canadian departments or divisions of EM associated with a general FRCP-EM training program surveyed and documented active EM simulationbased research at their institutions and identified the perceived facilitators and barriers. Priorities for simulation-based research were generated by simulation-leads via a second survey; these were grouped into themes and finally endorsed by consensus during an in-person meeting of simulation leads. Priority themes were also reviewed by senior simulation educators.

Results: Twenty simulation-leads representing all 14 invited institutions participated in the study between February and May, 2018. Sixty-two active, simulation-based research projects were identified (median per institution $=4.5$, IQR 4), as well as six common facilitators and five barriers. Forty-nine priorities for simulation-based research were reported and summarized into eight themes: simulation in competencybased medical education, simulation for inter-professional learning, simulation for summative assessment, simulation for continuing professional development, national curricular development, best practices in simulation-based education, simulation-based education outcomes, and simulation as an investigative methodology.

Conclusion: This study summarized simulation-based research activity in EM in Canada, identified its perceived facilitators and barriers, and built national consensus on priority

From the Departments of *Emergency Medicine, Queen's University, Kingston, ON; †Emergency Medicine, University of Saskatchewan, Saskatoon, SK; ¥Medicine, University of Toronto, St. Michael’s Hospital, Toronto, ON; §Emergency Medicine, McMaster University, Hamilton, ON; $\llbracket E m e r g e n c y$ Medicine, University of Manitoba, Winnipeg, MB; **Emergency Medicine, Western University, London, ON; ††Emergency Medicine, University of British Columbia, Vancouver, BC; ¥¥Family Medicine and Emergency Medicine, Universite de Sherbrooke, Sherbrooke, QC; §§Family Medicine and Emergency Medicine, Laval Universite, Quebec City, QC; ๆी氏Emergency Medicine, University of Alberta, Edmonton, AB; ***Emergency Medicine, University of Calgary, Calgary, AB; †††Family Medicine and Emergency Medicine, Universite de Montreal, Montreal, QC; $¥ \neq \neq E m e r g e n c y$ Medicine, University of Ottawa, Ottawa, ON; §§§Emergency Medicine, Dalhousie University, Halifax, NS; and the ITाTFamily Medicine, McGill University, Montreal, QC.

Correspondence to: Dr. Tim Chaplin, Department of Emergency Medicine, Queen's University Kingston Health Sciences Centre, 76 Stuart Street, Kingston, ON K7L 2V7 Email: chaplintim2@gmail.com

(C) Canadian Association of Emergency Physicians 
research themes. This represents the first step in the development of a simulation-based research agenda specific to Canadian EM.

\section{RÉSUMÉ}

Introduction: La simulation joue maintenant un rôle essentiel dans le système de soins de santé au Canada, avec différentes applications dans I'amélioration de la qualité, I'élaboration de systèmes ou la formation médicale. Or, son utilisation efficace est tributaire de la recherche fondée sur la simulation de qualité. L'étude visait donc à dresser le tableau des activités de recherche fondée sur la simulation, à cerner les facteurs facilitants et les obstacles ainsi qu'à établir les priorités de la recherche fondée sur la simulation, en médecine d'urgence (MU), au Canada.

Méthode: Des responsables de la simulation provenant de départements ou de divisions de MU, au Canada, associés au programme de formation générale du Collège royal des médecins et chirurgiens du Canada en MU ont mené une enquête sur les projets de recherche fondée sur la simulation en $\mathrm{MU}$, en cours dans leur établissement; les ont documentés, puis ont relevé différents éléments considérés comme des facteurs facilitants ou des obstacles. Ces responsables ont par la suite monté une liste de priorités de recherche fondée sur la simulation à l'aide d'une seconde enquête, après quoi cellesci ont été groupées en thèmes, puis acceptées par consensus au cours d'une réunion tenue en personne par ces mêmes experts. Les thèmes prioritaires ont également fait l'objet d'examen par des éducateurs chevronnés en simulation.

Résultats: Vingt responsables de la simulation, représentant les 14 établissements invités, ont participé à l'étude, entre février et mai 2018. Ont été relevés 62 projets actifs de recherche fondée sur la simulation (médiane par établissement : 4,5; écart interquartile : 4), 6 facteurs facilitants et 5 obstacles communs. Par la suite, I'enquête a permis de recenser 49 priorités de recherche fondée sur la simulation, groupées en 8 thèmes: la simulation dans la formation médicale axée sur les compétences, la simulation dans l'apprentissage interprofessionnel, la simulation dans l'évaluation sommative, la simulation dans la formation professionnelle continue, le développement du curriculum national, les pratiques exemplaires dans la formation fondée sur la simulation, les résultats de la formation fondée sur la simulation et la simulation comme moyen de recherche.

Conclusion: L'étude a permis de dresser le tableau des activités de recherche fondée sur la simulation en MU au Canada, de faire ressortir les éléments considérés comme des facteurs facilitants ou des obstacles, et d'atteindre un consensus national sur les thèmes prioritaires de recherche. Voilà qui constitue la première étape de l'élaboration d'un programme de recherche fondée sur la simulation, propre à la $\mathrm{MU}$ au Canada.

Keywords: Emergency medicine, simulation-based research

\section{INTRODUCTION}

Simulation plays an integral role in the Canadian healthcare system with applications in quality improvement, systems development, and medical education. Simulation is "a tool, device, or environment that mimics an aspect of clinical care," 1 and it has been embraced by the specialty of emergency medicine (EM) at every stage of medical training from undergraduate medical education to continuing professional development. ${ }^{2,3}$ Coincident with its increasing role in EM, simulationbased research has proliferated ${ }^{4}$ and evolved from studies demonstrating that simulation is an effective training methodology to exploring the translational outcomes of simulation-based curricula and programs. ${ }^{1,2,5-7}$ Highquality research is required to ensure the effective and efficient use of simulation in diverse contexts, and to discover and inform novel applications. ${ }^{4,7,8}$

Bond et al. ${ }^{9}$ described a simulation-based research agenda within EM in 2007, highlighting the importance of patient-centred initiatives, continuing medical education, and multicentre efforts to address skill transfer, the validity of simulation for assessment, debriefing techniques, and outcomes related to team performance. Cook et al. ${ }^{8}$ subsequently called for simulation-based research using comparative studies, validity studies, and qualitative methods. Further, Ilgen et al. ${ }^{2}$ identified the need to question optimal educational design and evaluate the cost-effectiveness of simulation interventions. Most recently, proceedings from the 2017 Academic Emergency Medicine consensus conference identified simulation-based research priorities that relate to patient safety and outcomes at the systems level. ${ }^{10}$

Although these research agendas provide broad direction, they are not specific to Canadian EM, and it has been difficult to relate their priorities to tangible outcomes. The Canadian context is particularly unique given the current national implementation of competency-based medical education across all postgraduate training programs $^{11,12}$ and the concomitant call for the increased use of simulation for training and assessment. ${ }^{13}$ Our objective was to summarize simulation-based research 
activity in Canada, identify its facilitators and barriers, and establish consensus for future simulation-based research priorities in Canadian EM.

\section{METHODS}

We conducted a survey-based study consisting of questionnaires and final consensus generation between February and May 2018. Simulation-leads from all 14 academic departments/divisions of EM associated with an adult Fellow of the Royal College of Physicians and Surgeons of Canada (FRCPC) residency training program were invited to participate. A simulation lead was defined as an EM faculty with either a formal simulationrelated title (i.e., Simulation Education Lead) or an individual with significant simulation expertise identified at his or her institution. Simulation-based research was defined as any scholarship ${ }^{14}$ that incorporates simulation as the study objective, content, or investigative method. ${ }^{7}$ This study was approved by the Health Sciences Research Ethics Board at Queen's University (REB \#6023280).

\section{Questionnaire 1 (01) - SBR activities, barriers, and facilitators}

Q1 (Supplemental Appendix A) was aimed to capture all current simulation-based research activity and describe the perceived facilitators, barriers, and successful strategies for conducting simulation-based research in Canadian EM. After piloting, simulation-leads administered Q1 at their institution to all EM faculty involved in scholarship related to simulation. Results were collated by two authors, and simulation-based research activity was grouped using a previously described framework. ${ }^{9}$ Perceived facilitators, barriers, and strategies were compiled and grouped into themes via an inductive thematic analysis.

\section{Questionnaires 2 (02) and 3 (03) - SBR priorities}

Q2 and Q3 were administered electronically to all simulation-leads. Q2 reflected the results of Q1 back to simulation-leads and asked them to generate a list of priorities for simulation-based research. Simulation-leads were encouraged to consider the goal of advancing the use of simulation in EM when generating simulation-based research priorities and asked to solicit the perspectives of other faculty and stakeholders within their respective simulation programs. Responses to Q2 were collated, reviewed for duplication, and summarized as priority research themes, using an inductive thematic analysis. Q3 reflected these themes back to simulation-leads and asked them to assign a "low priority" or a "high priority" to each, with an aim to prioritize future work in potentially limited resource environments. Simulation-leads distributed the list of themes to senior EM simulation-based educators within their institution, who were also asked to assign priority and recommend any additional themes.

\section{Consensus generation}

Simulation-leads met in-person and via the electronic platform Google Hangouts (Alphabet, California, USA) in May 2018 at the Canadian Association of Emergency Physicians (CAEP) Annual Conference with the purpose of achieving consensus on the themes and priority ranking. Consensus was defined a priori as unanimous agreement. If unanimous agreement could not be reached after discussion, that particular theme would be removed. Comments from senior simulation educators were reviewed, and suggestions for additional simulation-based research themes were incorporated if endorsed by consensus. In addition, example research questions were generated for each simulation-based research priority.

\section{RESULTS}

Twenty simulation-leads representing all 14 Canadian emergency departments or divisions with an FRCPCEM residency training program participated. Eight institutions had a single simulation-lead representative, and six institutions had two simulation-leads who worked together. All were practising EM faculty with FRCPC designation apart from one senior FRCPC-EM resident. Mean simulation-lead age was 36.7 (median 36) years, with a mean of 5.9 (median 4 ) years in practice. Fourteen of 20 simulation-leads had a fellowship in simulation, an advanced degree in medical education, or both.

Q1 identified 62 active simulation-based research projects from 14 institutions (median per institution $=4.5$, $\mathrm{IQR}=4$ ) that are listed in Supplemental Appendix B. Table 1 presents the distribution of these projects by categories and subcategories. Table 2 presents the summary themes from 34 facilitators, 41 barriers, and 28 strategies identified by simulation leads. 


\begin{tabular}{|c|c|}
\hline SBR category & SBR subcategory \\
\hline Education and training $(n=37)$ & $\begin{array}{l}\text { Instructional delivery and feedback }(16 / 37,42 \%) \\
\text { Procedural skill competency }(10 / 37,27 \%) \\
\text { Medical expert competency }(7 / 37,18.9 \%) \\
\text { Intrinsic role competency }(4 / 37,10.8 \%)\end{array}$ \\
\hline Evaluation and assessment $(n=22)$ & $\begin{array}{l}\text { Quality improvement/system-based initiatives }(10 / 22,45 \%) \\
\text { Evidence for the validity of simulation-based assessment }(8 / 22,36 \%) \\
\text { National processes }(4 / 22,18 \%)\end{array}$ \\
\hline Unique specialty topic $(n=3)$ & N/A \\
\hline
\end{tabular}

\begin{tabular}{|c|c|c|}
\hline SBR facilitators & SBR barriers & Strategies to overcome barriers \\
\hline $\begin{array}{l}\text { Department support for a simulation } \\
\text { director with oversight of SBR } \\
\text { Supportive simulation technicians and } \\
\text { staff } \\
\text { "Buy-in" from colleagues, learners, and } \\
\text { department for SBR } \\
\text { Access to research expertise (i.e., } \\
\text { research assistant and education } \\
\text { scientists) } \\
\text { Increased training for education research } \\
\text { Utilization of medical trainees as } \\
\text { investigators }\end{array}$ & $\begin{array}{l}\text { Lack of mentors with SBR expertise } \\
\text { Lack of protected time for SBR } \\
\text { Lack of dedicated SBR funding } \\
\text { Poor access to infrastructure (i.e., videotaping } \\
\text { equipment, simulation laboratory) } \\
\text { Lack of collaboration on SBR projects at the } \\
\text { departmental, institutional, and national levels }\end{array}$ & $\begin{array}{l}\text { Targeted faculty development opportunities } \\
\text { Clear expectations surrounding academic } \\
\text { contributions and protected clinical time } \\
\text { Access to "seed money" for SBR and } \\
\text { SBR-specific grants } \\
\text { National position statements that support } \\
\text { simulation scholarship as a priority } \\
\text { Establishing a collaborative platform for SBR } \\
\text { initiatives at both the local and national levels }\end{array}$ \\
\hline
\end{tabular}

All simulation-leads completed Q2 (response rate $100 \%$ ), generating 49 priorities for future simulationbased research, summarized into seven themes. Q3 (response rate $100 \%$ ) reflected these themes back to simulation-leads for prioritization and identified the following three as having the most "high priority" categorizations: simulation in competency-based medical education, simulation for interdisciplinary and interprofessional learning, and simulation for summative assessment, receiving 12, 10, and 7 "high priority" categorizations, respectively. Eleven senior simulation educators from five academic institutions reviewed the priority simulation-based research themes. Their prioritization aligned with that of the simulation-leads. One additional research priority was suggested by a senior educator: simulation as an investigative methodology.

Fourteen of $20(70 \%)$ simulation-leads representing 12 of $14(86 \%)$ institutions attended the consensus meeting. There was unanimous agreement with the categorization of simulation-based research priorities from Q3 and with the decision to add the research theme identified by the senior educator. The final list of eight simulation-based research, priority themes and example questions are presented in Table 3 in rank order based on prioritization assignment.

\section{DISCUSSION}

This study summarizes simulation-based research activity in Canadian EM and presents consensus priorities for scholarship from Canadian EM simulation educators. Simulation-based research is occurring in all but one FRCPC-EM training centre, with most activity focused on education and training, and a minority addressing evaluation and assessment. The reported barriers and facilitators of simulation-based research are reviewed in the following texts, followed by a contextualization of the eight priority themes for simulation-based research in EM in Canada (see Table 3). 


\begin{tabular}{|c|c|}
\hline SBR priority & Example research questions \\
\hline Simulation in CBME & $\begin{array}{l}\text { How can we most effectively use simulation to assess difficult to observe entrustable } \\
\text { professional activities (EPAs)? } \\
\text { How can simulation effectively supplement clinical experiences as defined by the RTEs and } \\
\text { competencies for each stage of CBD? }\end{array}$ \\
\hline $\begin{array}{l}\text { Simulation for interdisciplinary and } \\
\text { interprofessional learning }\end{array}$ & $\begin{array}{l}\text { How can in-situ simulation team training support the development of collective competencies } \\
\text { required by interprofessional healthcare teams? } \\
\text { What is the effect of regular team training on organizational culture? }\end{array}$ \\
\hline Simulation for summative assessment & $\begin{array}{l}\text { What is the role of simulation in a program of assessment? } \\
\text { How can simulation be incorporated as a medium or high-stakes assessment tool in } \\
\text { postgraduate EM training? }\end{array}$ \\
\hline $\begin{array}{l}\text { Simulation for continuing professional } \\
\text { development }\end{array}$ & $\begin{array}{l}\text { What features of simulation make it acceptable for practising physicians? } \\
\text { How can simulation best be used for re-certification or remediation? }\end{array}$ \\
\hline National curricular development & $\begin{array}{l}\text { What curricular subject areas and skills are best taught via simulation compared with traditional } \\
\text { strategies? }\end{array}$ \\
\hline Best practices in simulation-based education & $\begin{array}{l}\text { What is the optimal design of simulation-based procedural skills curricula in order to maximize } \\
\text { competency transfer and minimize skill decay? } \\
\text { What are the critical elements of debriefing, and how can debriefing optimize learning? }\end{array}$ \\
\hline Simulation-based education outcomes & $\begin{array}{l}\text { How does simulation-based learning relate to patient-level outcomes? } \\
\text { What are the most efficient (cost/benefit) simulation-based education interventions? }\end{array}$ \\
\hline Simulation as an investigative methodology & $\begin{array}{l}\text { How can simulation be leveraged most effectively as an investigative methodology? } \\
\text { What are the best practices in the use of simulation as an investigative methodology? }\end{array}$ \\
\hline
\end{tabular}

\section{Barriers and facilitators of simulation-based research}

Lack of funding and/or protected time from clinical service were two commonly cited barriers to simulationbased research activity across the country. This is consistent with prior literature identifying barriers to simulation-based research. ${ }^{7,15}$ If simulation-based research is to be a priority within EM, then funding in the form of specific grants, access to "seed" money to encourage new projects, and both departmental and institutional level support will be necessary. Comments from several simulation-leads also spoke to the importance of clarity within departments on deliverables and metrics specific to simulation-based research. A lack of mentorship with interest and expertise in simulationbased research was identified as an additional barrier to scholarship with a large variation between institutions. Simulation-based research "champions" within an institution create an environment that fosters further scholarship. Academic emergency departments might consider investing in an individual simulation-based research champion to motivate and focus others on a shared vision.

While all FRCPC-EM training programs report access to high-fidelity patient simulators and task-trainers, ${ }^{3}$ lack of access to additional infrastructure (e.g., reliable videotaping equipment, paid confederates, access to simulation laboratories for long periods, and supportive colleagues) required to conduct simulation-based research was indicated as a significant barrier. This speaks to the importance of articulating simulation-based research as a priority both within departments and simulation facilities. Further, collaboration at the departmental, institutional, and national level is needed to engage in simulation-based research. This can be facilitated through supporting a local champion, as discussed previously, developing a national position statement that supports simulationbased research as a priority in EM, and creating a platform at the national level that would enable inter-institutional sharing of ideas, resources, and data.

\section{Simulation in competency-based medical education}

As postgraduate EM training in Canada transitions to competency-based medical education, simulation will play an increasingly important role in both the delivery of high-quality training experiences and the assessment of entrustable professional activities. ${ }^{16}$ Competencybased medical education requires direct observation of learners; however, the clinical environment in EM is 
unpredictable and certain high-acuity events are rarely encountered, making them challenging to observe. ${ }^{17}$ Simulation can assist with these challenges by providing safe and reproducible experiences while also allowing expert observation, focused feedback, and deliberate practice. $^{18}$

\section{Simulation for interdisciplinary and interprofessional learning}

EM is practised within a social context involving interactions within teams and across disciplines and specialties. In situ simulation conducted within the actual workplace represents a unique opportunity to observe teams within their clinical environment ${ }^{19}$ and to evaluate team function within the broader healthcare system. ${ }^{20}$ Multiple studies demonstrate improvements in team performance following simulation-based training. ${ }^{21}$ Less is known about the translational impact of simulation-based team training on patient outcomes, though recent data are promising. $^{22,23}$ Simulation-leads agree that future simulation-based research should seek to establish the optimal role of both laboratory-based and in situ simulation, and how simulation can best serve team-based learning objectives and the assessment of "collective competencies."

\section{Simulation for high-stakes assessment}

The standardization, fidelity, and reproducibility of simulation make it well-suited for the assessment of clinical competence, ${ }^{5}$ and it will likely take on a greater role within competency-based medical education programs of assessment. In EM, this process is well underway, with most postgraduate program directors indicating they would be comfortable incorporating simulationbased assessments ${ }^{3}$ and several programs already using simulation-based examinations. ${ }^{24,25}$ Postgraduate training in anesthesia now includes a national standardized mid-training, simulation-based examination, ${ }^{26}$ and a similar examination for EM residents may complement current high-stakes assessment processes. Despite the potential benefits of using simulation for assessment, caution should be exercised given the current limited evidence for validity in higher-stakes decisions ${ }^{27}$ and the potential threat that the introduction of assessment may pose to the paradigm that the simulation suite is a "safe-space" for practice and failure. ${ }^{28}$

\section{Simulation for continuing professional development}

Simulation has been recognized as a powerful tool to facilitate learning beyond residency training. ${ }^{29,30}$ There is emerging evidence for procedural tasktraining, theatre-based simulation, and in situ simulation in continuing professional development to enhance both individual and team performance in critical situations. ${ }^{31}$ Recent culture shifts emphasize interprofessional collaboration and enhanced patient safety by developing more learner-driven and problem-based curricula, often delivered in a simulated environment. $^{32}$ As competency-based medical education moves beyond postgraduate training, simulation will assume a more prominent role in the maintenance of skills and development of new competencies. However, best practices and strategies for continuing professional development using simulation have not been described, creating a significant opportunity for innovation and scholarship.

\section{National curricular development}

Postgraduate EM training programs in Canada have embraced simulation-based education; however, there is great variation in its quantity and curricular delivery due to local differences in funding, resources, barriers, and clinical contexts. ${ }^{3}$ There is increasing pressure on postgraduate training programs to improve efficiency in training and to ensure that all training experiences are optimized for effective learning. ${ }^{33}$ A national simulation-based curriculum, similar to that derived for pediatric $\mathrm{EM}^{34}$ or the Nightmares Course ${ }^{35,36}$, would support the development of more ambitious simulation programs.

\section{Best practices in simulation-based education}

A previous systematic review identified 12 features and best practices of simulation-based medical education. ${ }^{5}$ Many of the research gaps identified therein were highlighted again in our study, including questions pertaining to the optimization of feedback for learning and how to best integrate simulation within multiple other teaching modalities. There is also merit in examining the use of standardized templates, the sharing of case content or entire curricula, ${ }^{36}$ and the development of valid and reliable simulation assessment tools for the EM-specific context. Similar to other pedagogical 
methods, simulation-based education is contextdependent, and best practices should be reflexive to allow for differing implementations and environments.

\section{Simulation-based education outcomes}

In order to justify the substantial costs associated with simulation, simulation-based research is needed to demonstrate improved educational outcomes. While there are data emerging to support this, studying the impact of simulation-based education has been a longstanding priority in the literature. ${ }^{4,5,37,38}$ Determining a return-on-investment of simulation in EM training will be important to assist administrators in the allocation of resources. Recently, Cook et al. ${ }^{39}$ argued that modern simulation-based research should focus on the "value proposition" of simulation-based education, with a goal to guide future research that focuses on outcomes and costs, measuring resource requirements, provider performance, patient outcomes, and impact on the healthcare organization. Assigning monetary value to simulation-based education is riddled with difficulties, but simulation-leads underscored the importance of this theme in order to provide a concrete justification.

\section{Simulation as an investigative methodology}

Simulation can be used as a research platform with several benefits over clinical-based research. ${ }^{7}$ The safety and ethical considerations related to clinical research are less relevant in the simulation lab. Furthermore, the research environment in a simulated setting can be controlled and reproduced in order to mitigate confounding influences and focus on the research variable in question. ${ }^{7}$ These features make it an attractive methodology to explore clinical and non-clinical research questions. For example, simulation has been used to identify latent safety threats in trauma resuscitations, ${ }^{40}$ inform staffing workload and responsibilities in a new emergency department, ${ }^{41}$ and develop and implement novel technologies. ${ }^{42,43}$

\section{Limitations}

This project has several limitations. Firstly, as a surveybased study coordinated by a self-selected group of simulation-leads, the perspectives of other stakeholders with respect to simulation-based research, although solicited, may not have been represented. In addition, the questionnaires were not anonymous. The resultant bias is a potential threat to the validity of the results. Secondly, the response rate to Q1 cannot be reported. We relied on individual simulation-leads to administer Q1 within their institution to all EM faculty involved in simulation scholarship, but the denominator was not collected. Thirdly, this project only surveyed departments of EM with an active FRCPC postgraduate program, so any important simulation-based research activity outside of these centres is not represented. Finally, we have not included the pediatric EM community, which has a well-established simulation-based research network. ${ }^{44}$

\section{CONCLUSION}

This project summarized the current state of simulationbased research activity in Canadian EM and outlined a set of research priorities for the future. This represents the first step in the development of a cohesive, focused simulation-based research agenda specific to Canadian EM. We aim to facilitate a national conversation that will foster collaboration and lead to the next wave of innovation in simulation-based education and scholarship.

Acknowledgements: The authors would like to thank the Kingston Resuscitation Institute for supporting the creation and initial meetings of the Emergency Medicine Simulation Educators Research Collaborative group.

Supplementary material: The supplementary material for this article can be found at https://doi.org/10.1017/cem.2019.416.

\section{REFERENCES}

1. McGaghie WC, Issenberg SB, Cohen ER, Barsuk JH, Wayne DB. Does simulation-based medical education with deliberate practice yield better results than traditional clinical education? A meta-analytic comparative review of the evidence. Acad Med 2011;86(6):706-11.

2. Ilgen JS, Sherbino J, Cook DA. Technology-enhanced simulation in emergency medicine: a systematic review and meta-analysis. Acad Emerg Med 2013;20(2):117-27.

3. Russell E, Hall AK, Hagel C, et al. Simulation in Canadian postgraduate emergency medicine training - a national survey. CFEM 2018;20(1):132-41.

4. Bradley P. The history of simulation in medical education and possible future directions. Med Educ 2006;40(3):254-62.

5. McGaghie WC, Issenberg SB, Petrusa ER, Scalese RJ. A critical review of simulation-based medical education research: 2003-2009. Med Educ 2010;44(1):50-63.

6. McGaghie WC, Issenberg SB, BarsukJH, Wayne DB. A critical review of simulation-based mastery learning with translational outcomes. Med Educ 2014;48(4):375-85. 
7. Cheng A, Auerbach M, Hunt EA, et al. Designing and conducting simulation-based research. Pediatrics 2014;133 (6):1091-101.

8. Cook DA. One drop at a time: research to advance the science of simulation. Simul Healthc 2010;5(1):1-4.

9. Bond WF, Lammers RL, Spillane LL, et al. The use of simulation in emergency medicine: a research agenda. Acad Emerg Med 2007;14(4):353-63.

10. Bond WF, Hui J, Fernandez R. The 2017 Academic Emergency Medicine Consensus Conference: catalyzing system change through healthcare simulation: systems, competency, and outcomes. Acad Emerg Med 2018;25(2):109-15.

11. Frank JR, Snell LS, Sherbino J. CanMEDS 2015 physician competency framework. Ottawa (ON): Royal College of Physicians and Surgeons of Canada; 2015.

12. Oandasan I. Advancing Canada's family medicine curriculum: triple C. Can Fam Physician 2011;57(6):739-40.

13. Holmboe ES, Sherbino J, Long DM, Swing SR, Frank JR. The role of assessment in competency-based medical education. Med Teach 2010;32(8):676-82.

14. Glassick CE. Boyer's expanded definitions of scholarship, the standards for assessing scholarship, and the elusiveness of the scholarship of teaching. Acad Med 2000;75(9):877-80.

15. Savoldelli GL, Naik VN, Hamstra SJ, Morgan PJ. Barriers to use of simulation-based education. Can $\mathcal{F}$ Anesth 2005;52 (9):944-50.

16. Royal College of Physicians and Surgeons of Canada (RCPSC). Entrustable professional activities for emergency medicine. Ottawa (ON): Royal College of Physicians and Surgeons of Canada; 2018.

17. Wang EE, Quinones J, Fitch MT, et al. Developing technical expertise in emergency medicine - the role of simulation in procedural skill acquisition. Acad Emerg Med 2008;15(11):1046-57.

18. Issenberg SB, McGaghie WC, Petrusa ER, Lee Gordon D, Scalese RJ. Features and uses of high-fidelity medical simulations that lead to effective learning: a BEME systematic review. Med Teach 2005;27(1):10-28.

19. Rosen MA, Salas E, Wu TS, et al. Promoting teamwork: an event-based approach to simulation-based teamwork training for emergency medicine residents. Acad Emerg Med 2008;15 (11):1190-8.

20. Petrosoniak A, Brydges R, Nemoy L, Campbell DM. Adapting form to function: can simulation serve our healthcare system and educational needs? Adv Simul 2018;3:8.

21. Armenia S, Thangamathesvaran L, Caine AD, et al. The role of high-fidelity team-based simulation in acute care settings: a systematic review. 7 Surg 2018;4(3):e136-e51.

22. Josey K, Smith ML, Kayani AS, et al. Hospitals with more-active participation in conducting standardized in-situ mock codes have improved survival after in-hospital cardiopulmonary arrest. Resuscitation 2018;133:47-52.

23. Andreatta P, Saxton E, Thompson M, Annich G. Simulationbased mock codes significantly correlate with improved pediatric patient cardiopulmonary arrest survival rates. Pediatr Crit Care Med 2011;12(1):33-8.

24. Hagel CM, Hall AK, Dagnone JD. Queen's University emergency medicine simulation OSCE: an advance in competency-based assessment. CFEM 2016;18(3):230-3.
25. Dagnone JD, Hall AK, Sebok-Syer S, et al. Competency-based simulation assessment of resuscitation skills in emergency medicine postgraduate trainees - a Canadian multi-centred study. Can Med Educ 7 2016;7(1):e57-e67.

26. Chiu M, Tarshis J, Antoniou A, et al. Simulation-based assessment of anesthesiology residents' competence: development and implementation of the Canadian National Anesthesiology Simulation Curriculum (CanNASC). L'evaluation par la simulation de la competence des residents an anesthesiologie: mise au point et mise en oeuvre d'un Programme national de simulation en anesthesiologie au Canada (CanNASC). Can 7 Anesth 2016;63(12):1357-63.

27. Cook DA, Brydges R, Zendejas B, Hamstra SJ, Hatala R. Technology-enhanced simulation to assess health professionals: a systematic review of validity evidence, research methods, and reporting quality. Acad Med 2013;88(6):872-83.

28. Rudolph JW, Raemer DB, Simon R. Establishing a safe container for learning in simulation: the role of the presimulation briefing. Simul Healthc 2014;9(6):339-49.

29. Jensen JB, Torsher LC. Simulation and continuing professional development. Int Anesthesiol Clin 2015;53(4):60-9.

30. Hobgood C, Mulligan T, Bodiwala G, et al. International Federation for Emergency Medicine model curriculum for continuing professional development. C7EM 2015;17(3):295-309.

31. Petrosoniak A, Auerbach M, Wong AH, Hicks CM. In situ simulation in emergency medicine: moving beyond the simulation lab. Emerg Med Australas 2017;29(1):83-8.

32. Kilian BJ, Binder LS, Marsden J. The emergency physician and knowledge transfer: continuing medical education, continuing professional development, and self-improvement. Acad Emerg Med 2007;14(11):1003-7.

33. Nousiainen MT, Caverzagie KJ, Ferguson PC, Frank JR, Collaborators I. Implementing competency-based medical education: what changes in curricular structure and processes are needed? Med Teach 2017;39(6):594-8.

34. Bank I, Cheng A, McLeod P, Bhanji F. Determining content for a simulation-based curriculum in pediatric emergency medicine: results from a national Delphi process. CFEM 2015;17(6):662-9.

35. McMurray L, Hall AK, Rich J, Merchant S, Chaplin T. The Nightmares course: a longitudinal, multidisciplinary, simulation-based curriculum to train and assess resident competence in resuscitation. 7 Grad Med Educ 2017;9(4):503-8.

36. Chaplin T, Egan R, Cofie N, et al. The implementation of a multi-institutional multidisciplinary simulation-based resuscitation skills training curriculum. Cureus 2018;10(11):e3593.

37. Okuda Y, Bryson EO, DeMaria Jr S, et al. The utility of simulation in medical education: what is the evidence? Mt Sinai 7 Med 2009;76(4):330-43.

38. McGaghie WC, Issenberg SB, Petrusa ER, Scalese RJ. Effect of practice on standardised learning outcomes in simulationbased medical education. Med Educ 2006;40(8):792-7.

39. Cook DA, Andersen DK, Combes JR, Feldman DL, Sachdeva AK. The value proposition of simulation-based education. Surgery 2018;163(4):944-9.

40. Fan M, Petrosoniak A, Pinkney S, et al. Study protocol for a framework analysis using video review to identify latent safety threats: trauma resuscitation using in situ simulation team training (TRUST). Br Med 7 Open 2016;6(11):e013683. 
41. Geis GL, Pio B, Pendergrass TL, Moyer MR, Patterson MD. Simulation to assess the safety of new healthcare teams and new facilities. Simul Healthc 2011;6(3):125-33.

42. McGraw R, Chaplin T, McKaigney C, et al. Development and evaluation of a simulation-based curriculum for ultrasound-guided central venous catheterization. CFEM 2016;18(6):405-13.
43. Szulewski A, Braund H, Egan R, et al. Through the learner's lens: eye-tracking augmented debriefing in medical simulation. $\mathcal{F}$ Grad Med Educ 2018;10(3):340-1.

44. Cheng A, Auerbach M, Calhoun A, et al. Building a community of practice for researchers: The International Network for Simulation-Based Pediatric Innovation, Research and Education. Simul Healthc 2018;13(3S Suppl 1):S28-34. 